\title{
Komponen Pemasaran Teh Herbal Bukit Hexon pada PT. Karya Pak Oles Tokcer Denpasar Bali
}

\author{
STEVI VIONA LUMBANTORUAN, I WAYAN WIDYANTARA, \\ PUTU UDAYANI WIJAYANTI
}

\author{
Program Studi Agribisnis, Fakultas Pertanian, Universitas Udayana \\ Jalan PB Sudirman Denpasar 80232 \\ Email: viona_sihombing@yahoo.com \\ widyantara@yahoo.com
}

\begin{abstract}
Marketing component of Herbal Tea Bukit Hexon at PT. Karya Pak Oles Tokcer Denpasar Bali
\end{abstract}

Marketing is a combination of four variables that are the core of the company's marketing system, consisting of product, price, place/distribution channels, and promotions. This study is aimed at identifying the components of marketing carried out by PT. Karya Pak Oles Tokcer and the constraints faced in marketing their products. The research location was selected by purposive sampling. Types of data collected included primary and secondary data. Data were collected by observation, interview, and documentation study. Data were analyzed descriptively and qualitatively. Based onthe results of research known component of the marketing done by PT. By Pak Oles lessening of the products that the company provides one type of packing to look more attractive in the eyes of connsumers, this type of use the packing box. The selling price of tea sold is determined based on a calculation of raw material usage, labor, production, operating costs and other costs. Based on the place/distribution channels, herbal tea Bukit Hexon marketed through direct marketing distribution channel and indirectly. Promotional products are made through direct marketing activities (sales counter), sales promotion (rebates and bonuses) and advertising (flyers, newspaper and radio from the company it self). Constraints facing the company consists of internal and external constraints. Internal constraints in terms of the promotion are less effective. External constraints in terms of competitors' similar products. Suggested the company should use the print media, better known by the public such as the Bali Post and electronic media such as ads on television so that are building relationships with the community and having a promotion more aggressively by opening a special stand tea sales as practiced by companies other tea products.

Keywords: marketing, herbal tea, promotion, component

\section{Pendahuluan}

\subsection{Latar Belakang}

Teh merupakan salah satu produk minuman terpopuler yang banyak dikonsumsi oleh masyarakat Indonesia maupun masyarakat dunia dikarenakan teh mempunyai rasa dan aroma yang khas, selain itu teh juga dipercaya mempunyai 
khasiat bagi kesehatan diantaranya mencegah kegemukkan, kanker dan kolesterol. Seiring dengan perkembangan zaman serta teknologi maka pada saat sekarang ini banyak sekali kita temui industri pengolahan teh dengan menghasilkan berbagai macam produk akhir seperti halnya teh kering, teh celup, dan bahkan teh dalam kemasan botol yang mana kesemuanya dapat memberikan kemudahan bagi kita untuk mengkonsumsi (Setyamidjaya D, 2000).Teh herbal tersedia dalam kemasan kaleng, kantong teh, atau teh herbal siap minum dalam kemasan kotak.Teh herbal juga sering diiklankan sebagai minuman kesehatan untuk menyembuhkan berbagai penyakit (Taylor, 2002). Mengantisipasi konsumen yang heterogen maka perusahaan perlu mengkelompokkan pasar menjadi segmen-segmen pasar, lalu memilih dan menetapkan segmen pasar tertentu sebagai sasaran, dengan adanya hal ini, maka perusahaan terbantu untuk mengidentifikasi peluang pasar dengan lebih baik, dengan demikian perusahaan dapat mengembangkan produk yang tepat, dapat menentu saluran distribusi dan periklanan yang sesuai dan efisien serta mampu menyesuaikan harga bagi barang atau jasa yang ditawarkan bagi setiap target pasar.

Menurut Kotler (2002), pemasaran merupakan hal yang paling penting dilaksanakan oleh perusahaan dalam usahanya menciptakan pasar untuk memperoleh kesempatan mendapatkan laba yang optimal dan menjaga kelangsungan hidup suatu usaha. Pemasaran adalah suatu proses sosial yang didalamnya individu dan kelompok mendapat apa yang masyarakat butuhkan dan inginkan dengan menciptakan, menawarkan, dan secara bebas menukarkan produk yang bernilai dengan pihak lain. Usaha dalam bidang apapun memerlukan dukungan konsep pemasaran yakni mencakup produk, harga, promosi dan distribusi (product, price, promotion, place), untuk mencapai tujuan pemasaran, maka keempat unsur tersebut harus saling mendukung antara satu dengan yang lainnya, tidak bisa hanya satu komponen saja yang diprioritaskan, sebab apabila perusahaan ingin memenuhi kebutuhan secara memuaskan maka harus didukung oleh keempat unsur di atas.Pemasaran merupakan sistem keseluruhan dari berbagai kegiatan bisnis atau usaha yang ditujukan untuk merencanakan, menentukan harga barang atau jasa, mempromosikannya, dan mendistribusikannya kepada konsumen dan bisa memuaskan konsumen (Tjiptono, 2001).

\subsection{Rumusan Masalah}

Berdasarkan latar belakang permasalahan di atas, maka dapat dirumuskan masalah sebagai berikut.

a. Bagaimana pemasaran yang dilakukan oleh PT. Karya Pak Oles Tokcer terhadap produk Teh herbal Bukit Hexon?

b. Apa kendala-kendala yang dihadapi oleh PT. Karya Pak Oles Tokcer dalam memasarkan produk teh herbal Bukit Hexon? 


\subsection{Tujuan Penelitian}

Berdasarkan latar belakang dan rumusan masalah tersebut, maka tujuan penelitian ini untuk mengetahui dua hal pokok sebagai berikut.

a) Pemasaranyang dilakukan oleh PT. Karya Pak Oles Tokcer terhadap produk teh herbal Bukit Hexon.

b) Kendala-kendala yang dihadapi oleh PT. Karya Pak Oles Tokcer dalam memasarkan produk teh herbal Bukit Hexon.

\section{Metode Penelitian}

\subsection{Lokasi dan Waktu penelitian}

Penelitian ini dilakukan pada bulan Desember sampai dengan Januari tahun2016 di PT. Karya Pak Oles Tokcer yang beralamat di Jalan Pulau Komodo No. 32-38 X Denpasar, Bali. Pemilihan lokasi penelitian dilakukan secara purposive sampling, yaitu penentuan lokasi secara sengaja dengan dasar pertimbangan tertentu. Pertimbangan tersebut didasari atas hal-hal sebagai berikut.

1. PT. Karya Pak Oles Tokcer merupakan salah satu perusahaan swasta yang bergerak dalam bidang produksi teh herbal Bukit Hexon.

2. Sejauh ini belum pernah dilakukan penelitian di perusahaan tersebut.

\subsection{Penentuan Informan Kunci}

Dalam penelitian ini dipilih secara sengaja tiga orang informan kunci yang terdiri atas satu orang kepala bagian produksi, satu orang kepala bagian administrasi \& keuangan, dan satu orang kepala bagian pemasaran. Informan kunci tersebut dipilih karena dianggap mampu memberikan keterangan yang lebih mendalam dan aktif memberikan informasi mengenai perusahaan dalam penelitian ini

\subsection{Metode Pengumpulan Data}

Metode pengumpulan data yang digunakan dalam penelitian ini dilakukan dengan cara sebagai berikut.

1. Pengamatan (observasi), dilakukan dengan cara mengadakan pengamatan secara langsung ke perusahaan untuk mendapatkan gambaran yang lebih jelas mengenai produk dan lokasi penelitian.

2. Wawancara, yaitu salah satu bentuk komunikasi yang dilakukan dengan metode tanya jawab secara langsung dengan informan kunci.

3. Studi dokumentasi, pengumpulan data yang dilakukan dengan cara melihat dan mencatat dokumen atau catatan yang berhubungan dengan penelitian.

\subsection{Jenis dan Sumber Data}

\subsubsection{Jenis data}

Jenis data yang dikumpulkan dalam penelitian ini adalah data kualitatif dan kuantitatif. Data kualitatif merupakan data yang tidak berupa angka hanya berupa uraian dan keterangan mengenai perusahaan seperti gambaran umum lokasi 
penelitian, tujuan perusahaan, dan struktur organisasi perusahaan. Data dapat dianalisis dan dihitung secara matematis seperti harga produk, data penjualan, dan jumlah tenaga kerja.

\subsubsection{Sumber data}

Sumber data yang dikumpulkan dalam penelitian ini adalah data primer dan data sekunder. Data primer merupakan sumber data yang diperoleh secara langsung (observasi) dari sumbernya, diamati, dan dicatat untuk pertama kalinya melalui wawancara seperti jenis produk, harga produk, data penjualan, jenis saluran pemasaran, wilayah pemasaran produk, kegiatan promosi, serta kendala-kendala yang dihadapi perusahaan. Data sekunder merupakan sumber data yang diperoleh secara tidak langsung melalui media perantara (diperoleh dan dicatat oleh pihak lain) dari instansi atau perusahaan dan buku-buku penunjang yang berhubungan dengan penelitian, internet, dan Dinas Pertanian Provinsi Bali.

\subsection{Variabel dan Pengukuran Variabel}

Komponen pemasaran teh herbal Bukit Hexon pada PT. Karya Pak Oles Tokcer, variabel, indikator, parameter dan pengukuran yang digunakan dapat dilihat pada tabel 1 .

Tabel 1.

Variabel, Indikator, Parameter, dan Pengukuran Komponen Pemasaran Teh Herbal Bukit Hexon pada PT. Karya Pak Oles Tokcer Denpasar.

\begin{tabular}{|c|c|c|c|}
\hline \multirow{3}{*}{$\begin{array}{l}\text { Variabel } \\
\text { Komponen } \\
\text { Pemasaran Teh } \\
\text { Herbal BukitHexon }\end{array}$} & Indikator & Parameter & Pengukuran \\
\hline & Produk & Jenis produk & Kualitatif \\
\hline & & Jumlah produksi & Kualitatif \\
\hline \multirow[t]{7}{*}{ Herbal BukitHexon } & Harga & Harga jual produk & Kuantitatif \\
\hline & & Data penjualan & Kuantitatif \\
\hline & Tempat & Jenis saluran distribusi & Kualitatif \\
\hline & & Wilayah pemasaran & Kualitatif \\
\hline & Promosi & Pemasaran penjualan & Kualitatif \\
\hline & & Promosi penjualan & Kualitatif \\
\hline & & Periklanan & Kualitatif \\
\hline \multirow{2}{*}{$\begin{array}{l}\text { Kendala-kendala } \\
\text { yang dihadapi }\end{array}$} & Internal & Kinerja perusahaan & Kualitatif \\
\hline & Eksternal & Pesaing produk sejenis & Kualitatif \\
\hline
\end{tabular}

\subsection{Analisis Data}

Analisis data yang digunakan dalam penelitian ini adalah analisis deskriptif kuantitatif dan kualitatif. Data kuantitatif adalah data yang berupa angka atau dapat dihitung yang meliputi perhitungan tentang penilaian terhadap pertanyaan yang diberikan. Data kualitatif adalah data yang tidak berupa angka atau data yang tidak dapat dihitung, tetapi merupakan keterangan yang berhubungan dengan masalah yang diteliti yang meliputi gambaran umum perusahaan dan struktur organisasi perusahaan. 


\section{Hasil dan Pembahasan}

\subsection{Pemasaran}

Pemasaran adalah seperangkat alat pemasaran praktis dan terkontrol yang dipandukan oleh perusahaan untuk menghasilkan respon yang diinginkan pasar sasaran. Komponen pemasaran terdiri atas segala sesuatu yang dapat dilakukan perusahaan untuk mempengaruhi permintaan produknya (Kotler dan Amstrong, 2001 dalam Armenia, 2007), untuk mengetahui proses komponen pemasaran yang dilakukan oleh PT. Karya Pak Oles Tokcer, digunakan empat variabel sebagai berikut (1) produk, (2) harga, (3) tempat/saluran distribusi, dan (4) promosi, dalam usaha memasarkan teh herbal Bukit Hexon, PT. Karya Pak Oles Tokcer menggunakan satu jenis kemasan, yaitu kemasan box. Pemasaran produknya sudah menjangkau secara lokal seluruh wilayah Bali dan beberapa wilayah di luar Bali (Jawa Timur, Kalimantan, Sumatera) dengan melakukan promosi melaui brosur, Koran Renon, dan radio dari perusahaan seperti radio Pak Oles Tokcer FM dan Bukit Hexon Raya FM.

\subsubsection{Produk (product)}

Adapun keunggulan dari produk teh herbal Bukit Hexon yang diberikan oleh PT. Karya Pak Oles Tokcer kepada konsumen. Data mengenai produk tersebut tersaji pada tabel 2 .

Tabel 2.

Jenis Produk yang dipasarkan oleh PT. Karya Pak Oles Tokcer Denpasar

\begin{tabular}{lc}
\hline Ciri-ciri Produk & $\begin{array}{c}\text { Jenis Produk } \\
\text { Teh Herbal B }\end{array}$ \\
\hline Berat & 2 gram /Sachet \\
Kemasan & Box(isi 25 Sachet) \\
Target Pasar & masyarakat umum \\
Masa Berlaku & \pm 1 tahun \\
\hline
\end{tabular}

Sumber : PT. Karya Pak Oles Tokcer

Berdasarkan data pada tabel 2, teh yang dipasarkan oleh PT. Karya Pak Oles Tokcer dikemas dalam satu jenis kemasan, yaitu menggunakan kemasan boxdengan isi 25 sachet teh dengan berat 2 gram/sachet. Teh herbal Bukit Hexon dipasarkan untuk semua kalangan masyarakat umum terutama bagi mereka yang gemar mengkonsumsi teh, pada kemasan teh juga terdapat kode produksi dan tanggal expiredteh, sehingga para konsumen dapat mengetahui sampai kapan masa berlaku teh tersebut.

\subsubsection{Harga (price)}

Harga merupakan unsur komponen pemasaran yang memberikan pemasukan atau pendapatan bagi perusahaan. Ketiga unsur lainnya (produk, distribusi, dan 
promosi) menyebabkan timbulnya biaya (pengeluaran). Hal ini dilakukan perusahaan dengan tujuan agar perusahaan memperoleh omset penjualan atau pendapatan semaksimal mungkin. Bukan hanya itu, sebuah usaha dalam bentuk apapun pasti menginginkan pengeluaran biaya yang sekecil-kecilnya dengan keuntungan yang sebesar-besarnya, sebab sebuah perusahaan dikatakan maju dan berhasil apabila omset penjualan produk atau jasanya terus meningkat seiring dengan meningkatnya laba perusahaan (Kotler, 2005).

Penetapan harga merupakan suatu masalah jika perusahaan akan menetapkan harga untuk pertama kalinya, atau ketika akan memperkenalkan produknya ke saluran distribusi baru (Kotler, 2005). Penetapan harga pokok teh herbal Bukit Hexon pada PT. Karya Pak Oles Tokcer berdasarkan pada kalkulasi pemakaian bahan baku, tenaga kerja produksi, biaya operasional dan biaya lain-lain. Adapun contoh penetapan harga yang digunakan PT. Karya Pak Oles Tokcer untuk menghitung harga jual satu box teh kemasan 50 gram sebagai berikut.

Adapun harga jual untuk kemasan produk teh herbal Bukit Hexon. Data selengkapnya dilihat pada tabel 3

\section{Tabel 3.}

Harga Jual Teh yang dipasarkan oleh PT. Karya Pak Oles Tokcer Denpasar Bali Tahun 2012 s.d 2015

\begin{tabular}{lcccc}
\hline $\begin{array}{l}\text { Tahun } \\
(\text { Gram })\end{array}$ & $\begin{array}{c}\text { Jenis Produk } \\
(\text { Rp)/Box }\end{array}$ & Kemasan & Berat & Harga \\
\hline 2012 & Teh Herbal Bukit Hexon & Box & 50 Gram & $18.000,00$ \\
2013 & Teh Herbal Bukit Hexon & Box & 50 Gram & $20.000,00$ \\
2014 & Teh Herbal Bukit Hexon & Box & 50 Gram & $25.000,00$ \\
2015 & Teh Herbal Bukit Hexon & Box & 50 Gram & $30.000,00$
\end{tabular}

Sumber : PT. Karya Pak Oles Tokcer.

Berdasarkan data pada tabel 3, tahun 2012 s.d 2015 harga jual teh kemasan box dengan berat 50 gram berkisar antara Rp 18.000,00 sampai Rp 30.000,00. Metode pembayaran dalam usaha pemasaran teh herbal Bukit Hexon yang diberikan oleh PT. Karya Pak Oles Tokcer kepada konsumen adalah pembayaran secara tunai.

\subsubsection{Saluran distribusi/tempat (place)}

Hasil pengamatan di lapangan dan hasil diskusi dengan kepala pemasaran Teh Herbal Bukit Hexon terdapat beberapa saluran distribusi yang dipakai oleh perusahaan sebagai berikut.

1. Saluran I

Perusahaan $\longrightarrow$ toko/pengecer $\longrightarrow$ konsumen

Pada saluran ini perusahaan menggunakan jasa tenaga marketing untuk mencari langganan sendiri atau mencari toko/pengecer kecil yang berminat untuk memasarkan produk perusahaan, kemudian tenaga marketing mengirim produk sesuai pesanan dan selanjutnya pihak toko akan menjual secara langsung ke 
konsumen, adanya tingkat harga tertinggi sehingga pihak toko atau pengecer bebas menjual produk perusahaan dengan harga yang sesuai dengan kemampuan toko atau pihak pengecer.

2. Perusahaan $\longrightarrow$ toko/koperasi $\longrightarrow$ konsumen

Pada saluran yang kedua ini, dari perusahaan produk langsung dijual kepada toko atau koperasi yang berminat memasarkan Teh Herbal Bukit Hexon tanpa adanya kontrak harga sehingga sama seperti saluran sebelumnya atau saluran pertama, sebelumnya toko atau koperasi yang sudah dipercaya dapat langsung memasarkan produk perusahaan kepada konsumen. Pada saluran ini terlihat lebih sederhana karena tidak melalui perantara tenaga marketing sehingga dapat menghemat biaya pemasaran yang dikeluarkan pihak perusahaan.

3. Perusahaan $\rightarrow$ konsumen

Penjualan dalam produk PT. Karya Pak Oles Tokcer juga menggunakan saluran langsung yaitu saluran dimana perusahaan tidak menggunakan jasa perantara dalam memasarkan produk tetapi langsung berhubungan dengan konsumen sebagai target penjualan produk. Hal ini dilakukan selain untuk lebih memperkenalkan dan mempromosikan Teh Herbal Bukit Hexon melalui konterkonter yang dimiliki oleh perusahaan tetapi juga sebagai penghematan biaya pemasaran baik biaya angkut ataupun biaya promosi. Pemasaran langsung, membeli biasanya adalah orang yang berprofesi bukan sebagai petani melainkan orang yang ingin mencoba khasiat dari Teh Herbal Bukit Hexon.

Berdasarkan penjelasan saluran distribusi di atas saluran I dan II adalah saluran yang efektif yang membukukan angka penjualan tertinggi pada laporan penjualan setiap bulannya. Pada saluran ini perusahaan dapat mencapai laba maksimal karena dapat menekan biaya pemasaran dan promosi sekecil-kecilnya.

\subsubsection{Promosi (promotion)}

Promosi merupakan kegiatan perusahaan untuk memperkenalkan produk dan bertujuan agar konsumen tertarik dan senang untuk membeli produk yang ditawarkan perusahaan pada calon pembeli, dalam memperluas pemasaran PT. Karya Pak Oles Tokcer khususnya produk Teh Herbal Bukit Hexon juga melakukan berbagai macam promosi yang dapat menarik konsumen. Promosi sangat penting untuk dilakukan oleh suatu perusahaan, karena dalam suatu aktivitas promosi perusahaan dapat membujuk konsumen agar menerima, membeli produk yang ditawarkan oleh perusahaan yang bersangkutan. Perusahaan memberikan kesempatan bagi konsumen untuk mengetahui keunggulan dari Teh Herbal Bukit Hexon yang ditawarkan. Apabila sesuai dengan selera, konsumen dapat langsung membelinya, dan mengikuti pameran-pameran baik diselenggarakan oleh pemerintah maupun swasta seperti pameran yang diselenggarakan Dinas Pertanian, baik kabupaten maupun provinsi. 


\subsubsection{Periklanan (advertising)}

Kegiatan dalam promosi ini PT. Karya Pak Oles Tokcer menggunakan media komunikasi untuk menyampaikan informasi kepada konsumen dalam satu waktu. Iklan merupakan alat utama bagi perusahaan untuk mempengaruhi konsumennya, dalam memasarkan produk Teh Herbal Bukit Hexon oleh PT. Karya Pak Oles Tokcer menggunakan media cetak seperti brosur dan koran (koran Renon dan koran Pak Oles) serta media elektronik seperti radio dari perusahaan yang terletak di tiga tempat, yaitu di Kabupaten Tabanan dengan gelombang 89,8 FM Pak Oles Tokcer, Kabupaten Klungkung dengan gelombang 100,5 FM Bokashi Raya, dan Kabupaten Buleleng dengan gelombang 92,8 FM Radion Hexon Agrocity, pada kemasan produk teh herbal Bukit Hexon juga terdapat logo/simbol Bukit Hexon yang merupakan kawasan bahan baku tersebut diambil dan ada gambar daun teh.

\subsection{Kendala-kendala yang dihadapi PT. Karya Pak Oles Tokcer}

Segala usaha pasti memiliki kendala yang selalu menjadi hambatan untuk perkembangan usaha yang sedang dilakukan oleh suatu perusahaan. Kendala tersebut harus bisa dipecahkan, apabila kendala tersebut dibiarkan maka usaha tersebut akan bangkrut, tetapi apabila kendala itu dapat dipecahkan, maka usaha tersebut akan berkembang dengan pesat. Kendala yang dihadapi PT. Karya Pak Oles Tokcer dalam memasarkan teh herbal Bukit Hexon dalam penelitian ini dapat dilihat dari segi internal perusahaan sebagai berikut.

1. Kendala internal

Kendala internal yang dihadapi oleh PT. Karya Pak Oles Tokcer adalah kinerja perusahaan ditinjau dari segi promosi yang kurang efektif, karena kurangnya penyampaian informasi kepada masyarakat. Gitosudarma (2000), menyatakan bahwa salah satu faktor yang menyebabkan promosi kurang efektif yaitu pemilihan media promosi kurang tepat. Media yang digunakan oleh PT. Karya pak Oles Tokcer dalam mempromosikan teh herbal Bukit Hexon hanya melalui media cetak seperti brosur dan koran (Koran Pak Oles dan Koran Renon) serta media elektronik seperti radio dari perusahaan yang terletak di tiga tempat, yaitu di Kabupaten Tabanan dengan gelombang 89,8 FM pak Oles Tokcer, Kabupaten Klungkung dengan gelombang 100,5 FM Bokashi \&Raya, dan Kabupaten Buleleng dengan gelombang 92,8 FM.

Media tersebut kurang dikenal masyarakat, sehingga mengakibatkan keberadaan teh herbal Bukit Hexon kurang diketahui oleh masyarakat. Selain itu PT. Karya Pak Oles Tokcer juga tidak pernah membuka stand khusus penjualan teh seperti yang dilakukan perusahaan teh lainnya. Sebagai contoh perusahaan produk teh herbal merah PT. Hadena Indonesia, dapat membuka stand khusus penjualan teh di supermarket, hotel dan seperti Tiara Dewata untuk mempromosikan produknya dan meningkatkan jumlah penjualan.

2. Kendala eksternal

Kendala eksternal yang dihadapi oleh PT. Karya Pak Oles Tokcer dalam memasarkan produk teh herbal Bukit Hexon adalah adanya pesaing produk sejenis 
seperti produk Herbal Life, Herbal Daun Cina, Herbal Angkak, Herbal Pasak Bumi Pasutri, Herbal Asmurat, Herbal Pegagan. Hal tersebut menyebabkan perusahaan harus bersaing cukup ketat khususnya dari segi kualitas produk yang dihasilkan sehingga mempengaruhi harga jual teh.

\section{Kesimpulan dan Saran}

\subsection{Kesimpulan}

Berdasarkan hasil penelitian yang telah dijabarkan pada bab sebelumnya, maka dapat disimpulkan beberapa hal sebagai berikut.

1. Pemasaran yang dilakukan PT. Karya Pak Oles Tokcer terhadap produk yaitu menggunakan kemasan box dengan berat 50 gram yang terdiri dari 25 sachet dengan berat 2 gram/sachet, dari segi distribusi perusahaan menggunakan dua jenis saluran distribusi pemasaran baik secara langsung maupun tidak langsung. Teh herbal Bukit Hexon dipasarkan diseluruh wilayah Bali, seperti Denpasar, Badung, Gianyar, Tabanan, Negara, Karangasem, Bangli dan Klungkung.

2. Kendala-kendala yang dihadapi PT. Karya Pak Oles Tokcer terdiri atas kendala internal dan eksternal. Kendala internal yang dihadapi adalah promosi yang kurang efektif,dan kurangnya penyampaian informasi kepada masyarakat. Kendala eksternal yang dihadapi adalah adanya pesaing produk sejenis seperti teh herbal. Hal ini memyebabkan perusahaan harus bersaing cukup ketat khususnya dari segi kualitas produk yang dihasilkan sehingga mempengaruhi harga.

\subsection{Saran}

Berdasarkan hasil penelitian yang telah dijabarkan pada bab sebelumnya, maka dapat disarankan beberapa hal sebagai berikut

1. Sebaiknya perusahaan terus melakukan kegiatan yang bersifat membangun hubungan dengan masyarakat, misalnya dengan menjadi salah satu sponsor pada acara seminar dan pameran expo.

2. Perusahaan sebaiknya melakukan promosi yang lebih gencar dengan membuka stand khusus penjualan teh.

\section{Ucapan Terimakasih}

Puji syukur penulis panjatkan kepada Tuhan Yang Maha Esa atas berkat dan kasih-Nya, penulis dapat menyelesaikan penelitian ini. Penelitian ini tidak mungkin terlaksana bahkan tercapai tanpa adanya partisipasi dari berbagai pihak. Maka dari itu, pada kesempatan ini penulis menyampaikan ucapan terima kasih kepada seluruh pihak yang telah membantu e-jurnal sehingga terselesaikan dengan baik.

\section{Daftar Pustaka}

Antara, Made. 2010. Metodologi Penelitian Sosial. (Bahan Ajar) Program Studi Agribisnis Fakultas Pertanian Universitas Udayana, Denpasar. 
Alf, R. 2004. Tanaman Perkebunan Teh Camelia sinensis L. USU : Press. Medan.

Alamsyah, N. A. 2006. Takhlukkan Penyakit dengan Teh Hijau. Pustaka: Penerbit Agrimedia. Jakarta.

Kotler, Armstrong. 2001. Manajemen Pemasaran. Gramedia, Jakarta.

Kotler, Philip. 2002. Manajemen Pemasaran. Edisi Milenium. Penerbit Prenhallindo. Jakarta.

Setyamidjaya D. 2000. Teh. Budi Daya dan Pengolahan Pascapanen. Penerbit Kanisius. Yogyakarta.

Tjiptono, Fandy. 2001. Strategi Peamasaran. Edisi 2. Andi Offset, Yogyakarta.

Taylor, E. 2002. Pengolahan Tanaman Herbal. Grafindo Persada. Jakarta.

William J. Stanton. 1991.Prinsip Pemasaran, Alih Bahasa Wilhelmus W. Bokowatun. Erlangga, Jakarta.

Wirartha, Made. 2006. Pedoman Penulisan Usulan Penelitian, Skripsi dan Tesis. Penerbit Andi. Yogyakarta. 